\title{
Correlation of Troponin Level (Troponin T, Troponin I) With PELOD-2 Score in Sepsis as a Predictive Factor of Mortality
}

\author{
Aileen C. Dauhan ${ }^{1 *}$, Aridamuriany D. Lubis ${ }^{1}$, Erna Mutiara ${ }^{2}$, Munar Lubis $^{1}$ \\ ${ }^{1}$ Department of Child Health, Faculty of Medicine, Universitas Sumatera Utara, Medan, Indonesia; ${ }^{2}$ Faculty of Public Health, \\ Universitas Sumatera Utara, Medan, Indonesia
} \begin{abstract}
Citation: Dauhan AC, Lubis AD, Mutiara E, Lubis M.
Correlation of Troponin Level (Troponin T Troponin II) With PELOD-2 Score in Sepsis as a Predictive Factor Mortality. Open Access Maced J Med Sci. 2019 Dec 15; 7(23):4072-4077.

https://doi.org/10.3889/oamjms.2019.806

Keywords: Troponin; PELOD-2; Sepsis; Mortality

*Correspondence: Aileen Clarissa Dauhan. Department of Child Health, Faculty of Medicine, Universitas aileen.clarissa.dauhan@gmail.com

Received: 13-Jun-2019; Revised: 20-Oct-2019; Accepted: 21-Oct-2019; Online first: 13-Dec-2019

Copyright: ๑ 2019 Aileen C. Dauhan, Aridamuriany D. ubis, Erna Mutiara, Munar Lubis. This is an open-access ander the terms of the Creative License (CC BY-NC 4.0)

Funding: This research did not receive any financial

Competing Interests: The authors have declared that no competing interests exist
\end{abstract}

\begin{abstract}
BACKGROUND: Sepsis in children with cardiovascular involvement can increase mortality. Recently, many studies have been conducted to investigate troponin as an early marker of myocardial dysfunction, associated with pediatric sepsis score. Pediatric Logistic Organ Dysfunction 2 (PELOD-2) score is recent scoring to assess organ dysfunction in sepsis children.

AIM: To determine the correlation between troponin T, troponin I with PELOD-2 score in sepsis as a predictive factor of mortality.

METHODS: A prospective cohort study was conducted on sepsis children in PICU Haji Adam Malik Genera Hospital, Medan. Assessment of PELOD-2 score, serum troponin T, and troponin I levels performed on the first day and 48 hours after sepsis was diagnosed. Patients were observed until moved to the ward or died.

RESULTS: A group of 41 subjects were recruited in this study. Troponin T level at 24 hours did not correlate with PELOD-2 scores. Troponin T level at 48 hours was positively correlated with PELOD-2 score $(r=0.771, p<$ $0.001)$ and had a significant association with the mortality rate $(p<0.001)$. Troponin $T$ at 48 hours could be used as a predictive factor of mortality (AUC $86.4 \%, p<0.001$ ) with a cut-off point of $40.3 \mathrm{ng} / \mathrm{mL}$ ( $76 \%$ sensitivity, $75 \%$ specificity, RR 2.48). Troponin I levels at 24 and 48 hours also had strong correlation with PELOD-2 score $(r=$ $0.326, p=0.037 ; r=0.691, p<0.001$ ) and could be used as a predictor of mortality in pediatric patients with sepsis (AUC 74.8\%, p 0.008; AUC 92.6\%, p < 0.001). The cut-off point of troponin I at 24 hours was $0.075 \mathrm{ng} / \mathrm{mL}$ (68\% sensitivity, $68.8 \%$ specificity, RR 1.84$)$ and at 48 hours was $0.125 \mathrm{ng} / \mathrm{mL}(80 \%$ sensitivity, $81.3 \%$ specificity, RR 3.13).
\end{abstract}

CONCLUSION: Serum troponin T and troponin I levels at 48 hours have positive correlation with PELOD-2 score as a predictive factor of mortality in pediatric patients with sepsis.

\section{Introduction}

Sepsis is a life threatening organ dysfunction that caused by immune disregulation of infection. Sepsis is the most common cause of morbidity and mortality in children [1]. According to the Sepsis Prevalence Outcomes and Therapies (SPROUT) study in 2015, the most common cause of infection came from the respiratory system (40\%), while organ dysfunction occurred in $67 \%$ of children with sepsis [2]. Research by Proulx et al found that systemic inflammatory response syndrome (SIRS) occurred in $82 \%$ treated patients in a pediatric intensive care unit (PICU), in which $23 \%$ of patients had sepsis, $4 \%$ of severe sepsis, and $2 \%$ of septic shock [3]. In Cipto Mangunkusumo Hospital PICU , as many as $19.3 \%$ of 502 pediatric patients treated experienced sepsis with a mortality rate of $54 \%$ [4]. Salim et al., in Haji Adam Malik Hospital PICU (RSHAM), Medan, showed the presentation of sepsis in boys was higher than girls, the highest age was 1 to 50 months, and the mortality rate was $42 \%$ [5].

Untreated sepsis can progress to septic shock and end in multi-organ failure such as brain, kidney, liver and cardiovascular system. Sepsis with the involvement of the cardiovascular system will increase mortality by $70 \%$ to $90 \%$. Cardiovascular dysfunction in sepsis occurs in 2-3 days after onset of sepsis, which is characterized by decreasing left ventricular ejection fraction (LVEF). Sepsis is associated with acute myocardial damage. Some studies have shown cardiac ventricular dilatation in sepsis [6], [7]. Assessment of cardiac function disorders using echocardiography is most often performed, but requires subjective ability by trained experts. In 
addition, there is often difficulty in radiographic support modalities within the first 24 hours [8]. Therefore, the idea arises to use biomarkers of cardiac dysfunction detect myocardial disorders and provide prognostic information in sepsis.

In adult patients, troponin is one of biomarker that have high sensitivity and can even show small myocardial damage. Troponins assessed were troponin $\mathrm{T}$ (cTnT) and troponin I (cTnl). Troponin T had sensitivity $99 \%$ with specificity $78 \%$, meanwhile for cTnl the sensitivity was $96 \%$ with specificity $88 \%$. The cTnT and cTnl levels increased in 3 hours after myocardial injury, but cTnT lasted longer than cTnl [8]. Various studies of troponin in adult sepsis have been carried out, but not much research has been done on children.

Organ dysfunction in sepsis can be assessed by using the pediatric logistic organ dysfunction score (PELODS) which assessed 6 systems organ with 12 variables to assess the degree of diseases [9]. In 2013, Letreutre et al. validated PELODS into PELOD2. Organ dysfunction was based on PELOD scores -2 level $\geq 11$ because it is associated with increased mortality as $30.5 \%$. At type B or C health centers, the cut-off for PELOD-2 score is $\geq 7$ [10].

The objectives of this study were to evaluate correlation between troponins ( $\mathrm{TnT}$ and $\mathrm{Tnl}$ ) level with PELOD-2 score in children with sepsis as a predictive factor of mortality.

\section{Methods}

A prospective cohort study was conducted at pediatric intensive care unit (PICU) Haji Adam Malik Hospital, Medan, North Sumatera, in October 2017March 2018. Samples were patients aged 1 month- $\leq$ 18 years that treated at PICU and diagnosed with sepsis. The exclusion criteria were patient with heart disease, either congenital or acquired, based from anamnesis, physical findings, or $\mathrm{x}$-ray. Samples were obtain by consecutive sampling. This study was approved by the Health Research Ethical Committee, Medical School, Universitas Sumatera Utara.

After get consent from the parents, blood sampling was done for all subjects. Full blood count, blood culture, blood gas analysis, lactat serum, creatinine, TnT and Tnl level at the first 24 hours were examined. All the blood examination except culture were reassess in 48 hours of the PICU stay. Calculation of PELOD-2 score was made for the first 24 hours and 48 hours. Then the subjects were followed up during treatment, until moved into the ward or died.

Data analysis was done with statistical software SPSS 20.0. Univariate analysis was done for subject charateristic. Spearman's correlations were used to examine the association between troponin level and PELOD-2 score. Differences in the troponin level and mortality were tested with Mann Whitney Utest. Statistical calculation was done at 95\% confidence interval and $p$-level $<0.05$ was considered significant. Diagnostic test was done to examine cut off troponin, receiver operator curve (ROC), areas under the curve (AUC), and relative risk (RR) troponin as predictive value of mortality in pediatric sepsis.

\section{Results}

\section{Study Participants}

A total of 43 patients were recruited, 2 patient died at first 24 hours in PICU, 41 patients were analized in this study. Patient characteristics distribution can be seen in the Table 1.

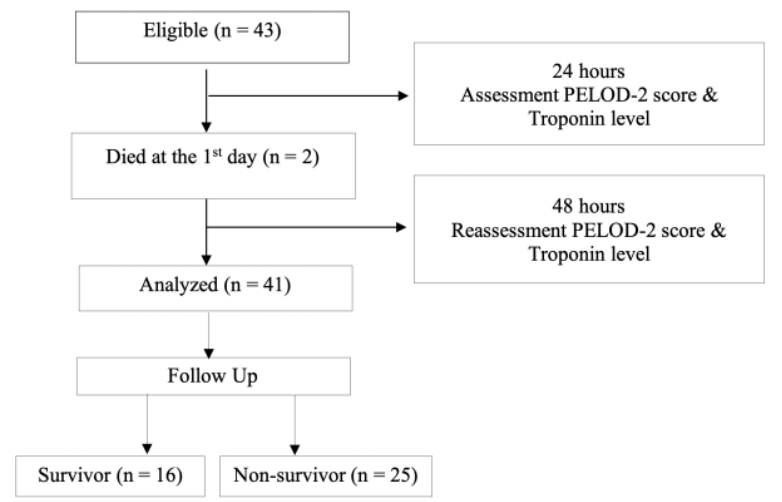

Figure 1. Study flow chart

There were 19 boys and 22 girls with median age 5.5 years old (interquartile range 0.08 to 17). Overall mortality rate was $61 \%$, with central nervous system was the most common primary infection source. Only 19 (39\%) patients with sepsis has positive blood culture.

Table 1: Baseline subject characteristics

\begin{tabular}{lc}
\hline Charateristics & Samples \\
$\mathrm{n}=41$
\end{tabular}




\section{Correlation between Troponin Level and PELOD-2 Score}

Table 2 shows correlation between troponin level and PELOD-2 score. From this study, there is no correlation between cTnT level and PELOD-2 score at 24 hours. Troponin T level at 48 hours and cTnl level at 24 and 48 hours have positive correlation with PELOD-2 score $(r=0.771, p<0.001 ; r=0.326, p=$ $0.037 ; r=0.691, p<0.001$, respectively).

Table 2: Correlation of troponin level and PELOD-2 score

\begin{tabular}{lccc}
\hline & Median (Min-Max) & $\mathrm{r}$ & $\mathrm{p}^{*}$ \\
\hline 24 hours & & & \\
PELOD-2 score & $8(1-21)$ & & \\
Troponin T level & $36.6(0.68-177)$ & 0.137 & 0.394 \\
Troponin I level & $0.1(0-1.1)$ & 0.326 & 0.037 \\
48 hours & $9(1-24)$ & & \\
PELOD-2 score & $42(1.97-233)$ & 0.771 & $<0.001$ \\
Troponin T level & $0.2(0-3-1)$ & 0.691 & $<0.001$ \\
Troponin I level & & &
\end{tabular}

\section{Association of Troponin Level and Mortality}

Troponin $\mathrm{T}$ level at 24 hours has no association with mortality, but there is significant association cTnT level at 48 hours and Tnl level with mortality. From all died subject in this study, both cTnT and cTnl level at 48 hours were higher than survivor children. Table 3 . Showed association of troponin level and mortality.

Table 3: Association of troponin level and mortality

\begin{tabular}{lccc}
\hline & $\begin{array}{c}\text { Survivor } \\
\text { Median (Min-Max) }\end{array}$ & $\begin{array}{c}\text { Non Survivor } \\
\text { Median (min-max) }\end{array}$ & $\mathrm{p}^{* *}$ \\
\hline 24 hours & & & \\
Troponin T $(\mathrm{ng} / \mathrm{mL})$ & $38(0.68-107)$ & $36.2(12.9-177)$ & 0.968 \\
Troponin I $(\mathrm{ng} / \mathrm{mL})$ & $0(0-0.93)$ & $0.33(0-1.11)$ & 0.007 \\
48 hours & & $53(13-233)$ & $<0.001$ \\
$\quad$ Troponin T $(\mathrm{ng} / \mathrm{mL})$ & $24.2(1.97-46)$ & $0.7(0-3.11)$ & $<0.001$ \\
$\quad$ Troponin I $(\mathrm{ng} / \mathrm{mL})$ & $0(0-0.26)$ & &
\end{tabular}

\section{Troponin Level as a Predictive Factor of Mortality}

Troponin level at 48 hours had well power as a predictive factor of mortality in chidren with sepsis with cTnT level cut-off point at 48 hours was 40.3 $\mathrm{ng} / \mathrm{mL}(76 \%$ sensitivity, $75 \%$ specificity, RR 2.48$)$, (Fig. 2).

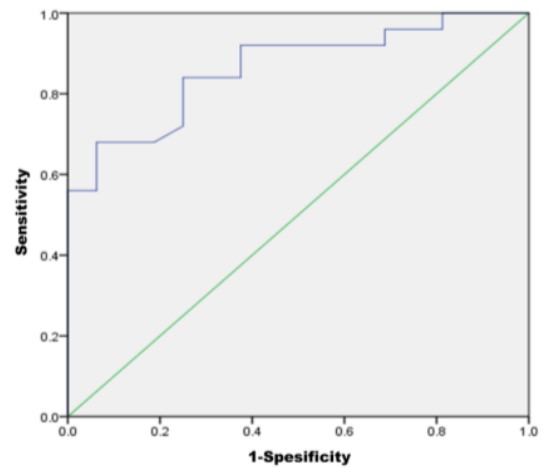

Figure 2: ROC curve of troponin T level at 48 hours (AUC $86.4 \%, p$ $<0.001,95 \% \mathrm{Cl} 0.75-0.97$ )
Troponin level at 48 hours had well power as a predictive factor of mortality in chidren with sepsis with cTnl level $0.125 \mathrm{ng} / \mathrm{mL}$ (80\% sensitivity, $81.3 \%$ specificity, RR 3.13), (Fig. 3).

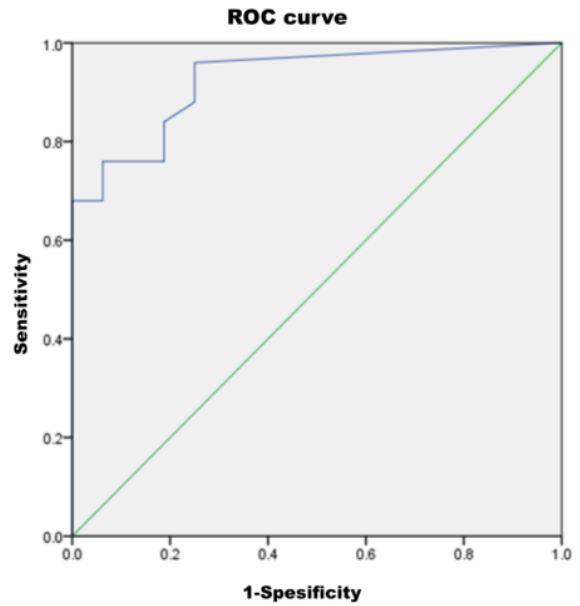

Figure 3. ROC curve of troponin I level at 48 hours (AUC 92.6\%, $p$ $<0.001,95 \% \mathrm{Cl} 0.85-1.0$ )

\section{Discussion}

Sepsis is the major cause of death in children within last two decades, especially in developing countries. The mortality rate in children with sepsis can reach $5-20 \%$. More than $50 \%$ of death from sepsis are associated with severe infections such as pneumonia, diarrhea, and malaria. The high mortality rate in low-income countries is related to the delay in the sepsis diagnosis and treatment [1], [11].

The study by Wang et al., found that children with sepsis and severe sepsis in China the mortality rate approximately $34.6 \%$, and two-thirds of deaths occurred within 72 hours of treatment [12]. Another study conducted by Jaramillo-Bustamante et al., said that there were $50 \%$ of pediatric patients treated in PICU with septic shock and $40 \%$ of them experienced MODS, with a high mortality rate of $34 \%$ [13]. Largescale research by SPROUT in 2015 found the mortality rate due to sepsis in children worldwide was $25 \%$ [14].

From this study, 41 patients with sepsis who were treated in PICU Haji Adam Malik Hospital, 25 patients $(61 \%)$ died. The most causes of sepsis are central nervous system infections (34.1\%) and infections after surgery (29.3\%). Mortality rate in this study was higher than the previous study conducted in PICU Haji Adam Malik Hospital in 2012 by Salim et al., with mortality rate was $42 \%$ [5].

Pediatric logistic organ dysfunction scores are used to assess organ dysfunction in pediatric 
population. The latest version that has been revised and validated in large-scale research with good calibration is PELOD-2 [10]. Karam et al., in his study found that changes in PELOD-2 scores assessed serially were related to the probability of death [15]. Assessment of PELOD-2 scores in this study was carried out within first 24 hours after diagnosis of sepsis in PICU and after 48 hours of therapy. The PELOD-2 score assessed at 24 hours and 48 hours had a significant relationship with mortality $(p=0.008$; $p<0.001$ ). The PELOD-2 score in sepsis patients who died was higher than that of survive patients. Assessment of PELOD-2 scores in this study was conducted in addition to predicting the occurrence of mortality, and also to evaluate therapy progress through biomarkers of myocardial dysfunction in sepsis. Klag et al., found that evaluation for successful antimicrobials therapy in septic patients can be done after 48 hours, which is one of it sign characterized by a decrease in sepsis biomarkers [16].

Troponin $\mathrm{T}$ and troponin $\mathrm{I}$ are cardiac myofibrin compounds that studied with regard to myocardial dysfunction in sepsis. Myocardial dysfunction, characterized by left ventricular systolic and diastolic disorders, is a complication of early sepsis, especially in patients with sepsis shock [17]. In addition, the cardiovascular system itself is part of the calculation of the scores of new PELOD-2 organ dysfunction [10]. Physiological and metabolic changes occur in sepsis patient, such as impaired coronary blood flow, decreased oxygen levels, hypokinetic heart wall, and ventricular dilatation [18]. Macrocirculation of cardiac blood flow will increase in septic shock, while microcirculation decreases. The disruption of blood flow will result in a decrease in perfusion of the heart muscle, resulting in myocardial dysfunction and troponin release from cardiac myocytes [19], [20].

This study showed that troponin $T$ from 24hour assessment did not had a significant correlation with the PELOD-2 score. Meanwhile troponin T and troponin I levels showed a statistically significant correlation with the PELOD-2 score if measured at 48 hours. The results from this study were the same as the case control study by Hassan et al., where cTnT levels were related to the severity of patients and had a positive correlation with PIM2 scores $(r=0.67 ; p<$ 0.05 ) [21]. Lodha et al., study showed serial cTnl levels at 24 hours, 48 hours, and 96 hours higher in pediatric patients with sepsis. Also, the level of $\mathrm{CTnl}$ at the time of admission had a positive correlation with the PIM2 score $(r=0.51, p=0.03)$ [22].

Differences in type of infection, methods of troponin levels examination, significant intersection points for troponin, and timing of blood sampling will affect troponin results. In addition, a decrease in blood pressure is a further manifestation of low cardiacoutput in children with septic shock. Heart blood flow will be maintained in the initial phase by vasoconstriction, increased heart rate, and reduced peripheral perfusion. In untreated sepsis, there will be a hemodynamic disruption so that the perfusion of the heart muscle will decrease and stimulate troponin release [23]. Increased troponin levels in blood correlate with impaired heart function, increase the needed for inotropic drugs, and the severity of the disease in critically ill pediatric patients with sepsis shock [24].

In a prospective study by Eldeen et al. in adult patients with sepsis treated in the ICU, cTnl levels correlated with the Acute Physiologic Assessment and Chronic Health Evaluation (APACHE) score with $r=$ $0.71, p=0.0001$. Assessment of organ dysfunction using the Sequential Organ Failure Assessment (SOFA) score on the first and second days of treatment also showed a significant correlation with cTnl $(r=0.69, r=0.64 ; p=0.0001)$. APACHE II and SOFA scores can be used as predictor scores for mortality $(p=0.0001)$, while cTnl alone cannot be predicted as a mortality $(p=0.29)$ [25]. Abnormalities of troponin levels in sepsis are associated with increased morbidity and mortality. Data from metaanalysis by Sheyin et al., obtained from 1857 patients, death occurred in $60.5 \%$ of sepsis patients and $38.9 \%$ of septic shock patients with elevated troponin levels. Increased troponin levels will increase almost twice the risk of death [26].

This study showed troponin $\mathrm{T}$ and troponin I levels at 48 hours correlated with mortality. The ROC and AUC curves showed that troponin T levels at 24 hours could not be used as a predictor factor for mortality of children with sepsis (AUC $50.04 \%$, p $0.97)$. Whereas in the 48-hour measurement, troponin $\mathrm{T}$ levels could be used as predictors of mortality in children with sepsis (AUC 86.4\%, $p<0.001$ ). Troponin I levels at 24 hours and 48 hours can be used as predictors of mortality (AUC 74.8\%, p 0.008; AUC $92.6 \%, p<0.001)$. For both troponins, it is better to examine troponin levels in the first 48 hours because statistically having a good AUC (> $80 \%$ ). Same result was stated in meta-analysis study by Bessière et al., that troponin could be a prognostic factor in septic patients and increase in troponin levels was associated with an increase in mortality rate, with AUC $68 \%(\mathrm{Cl} 0.63-0.71)$ [27]. This meta-analysis of 13 studies with 1227 samples had not been able to determine the optimal cut-off point for adult patients, while research on children are still limited.

The cTnT level at 48 hours in this study, which could predict mortality, was more than 40.3 $\mathrm{ng} / \mathrm{mL}$ (76\% sensitivity and $75 \%$ specificity) and $\mathrm{cTnl}$ level was more than equal to $0.125 \mathrm{ng} / \mathrm{mL}$ (sensitivity $80 \%$, specificity $81.3 \%$ ). Gurkan et al., study, in pediatric patients treated in PICU, concluded that CTnI measurements could evaluate the presence of myocardial dysfunction in cut-offs $\geq 0.6 \mathrm{ng} / \mathrm{ml}$ (sensitivity $93.3 \%$, specificity $46.2 \%$ ) [28]. However, that study found that there was no significant association between cTnl levels and mortality of pediatric patients with sepsis. Whereas there have 
been no studies to determine cTnT levels as predictors of mortality in children.

Meta-analysis study by Sheyin et al., found $38.9 \%$ of septic patients with increased troponin were died compared with $22.1 \%$ of sepsis patients without elevated troponin (RR 1.91; 95\% Cl: 1.65-2.22) [26]. This was similar to a meta-analysis study by Bessiere et al., [17]. Increased troponin levels will increase the risk of death in patients with sepsis (OR 1.92; Cl 1.352.47). According to John et al., patients with positive troponin had a mortality of $32.2 \%$ in 28 days, which was greater than negative troponin $13.2 \%$ ( $p<$ 0.0001) [29]. Multivariate analysis showed that troponin was an independent prognostic factor of mortality with OR 2.02 .

In this study, the likelihood of mortality in septic patients with troponin $\mathrm{T}$ levels at 48 hours more than $40.3 \mathrm{ng} / \mathrm{mL}$ was 2.48 times greater $(95 \% \mathrm{Cl} 1.26$ 4.89). Whereas troponin I measurements at 48 hours had relative risk (RR) $3.13(95 \% \mathrm{Cl} 1.46-6.70)$. This means that at a 48-hour examination, patients with troponin I levels greater than $0.125 \mathrm{ng} / \mathrm{mL}$ would have a 3.13 times greater mortality than those with troponin I levels less than $0.125 \mathrm{ng} / \mathrm{mL}$.

Some limitations in this study are variations in the course of the disease and the severity of the disease when the patient firstly diagnosed with sepsis was very broad, resulting in a wide range of data. This study also performed troponin examination only twice, at the beginning of PICU treatment and at 48 hours. In addition, measurements of troponin should be followed by examination of myocardial dysfunction such as echocardiography or other hemodynamic assessments. Assessment of myocardial dysfunction with various modalities is expected to be one of the references for the provision of optimal interventions for cardiovascular system disorders in sepsis.

Research on the level of troponin in the pediatric population is still very limited, therefore one of the advantages of this study is that it can provide a cut-off point for troponin levels that can be referred to in a population of children with sepsis. This study also investigated the correlation of troponin level as a marker of myocardial dysfunction with PELOD-2 score that currently used to assess organ dysfunction in pediatric sepsis, and it has never been studied before.

With repeated measurements, this study can show the course of the severity of an illness in children suffering from sepsis including predicting mortality. Although the variation in the course of the disease and the severity of the disease when diagnosed with sepsis were limitation for this research, but also became an advantage, because it is appropriate and can be used in daily clinical practice. Repeated measurements can also be used to evaluate therapy progress. Consideration for treatment changes can be done by physician with reference of increased troponin levels and PELOD-2 scores in pediatric patients with sepsis.
In conclusion, serum troponin $\mathrm{T}$ and troponin I levels at 48 hours have positive correlation with PELOD-2 score as a predictive factor of mortality in pediatric patients with sepsis.

\section{References}

1. Dezouza DC, Barreira ER, Faria LS. The epidemiology of sepsis in childhood. Shock. 2017; 47:2-5.

https://doi.org/10.1097/SHK.0000000000000699 PMid:27454387

2. Weiss SI, Fitzgerald JC, Maffei FA. Discordant identification of pediatric severe sepsis by research and clinical definition in the SPROUT international point prevalence study. Crit Care. 2015; 19:325-34. https://doi.org/10.1186/s13054-015-1055-x PMid:26373923 PMCid:PMC4572676

3. Proulx F, Fayon M, Farell CA,LAcroix J, Guthier M. Epidemiology of sepsis and multiple organ dysfunction syndrome in children. CHEST 2006; 109(4);1033-37. https://doi.org/10.1378/chest.109.4.1033 PMid:8635327

4. Priyatiningsih DR, Latief $A$, Pudjiadi $A H$. Karakteristik sepsis di pediatric intensive care unit RSUPN dr. Cipto Mangunkusumo. Jakarta: Fakultas Kedokteran Universitas Indonesia; 2016.

5. Salim E, Lubis M, Ali M. Hubungan antara kadar troponin T dan mortalitas pada anak syok sepsis yang dirawat di PICU. [tesis]. Medan: Program Magister Kedokteran Klinik Ilmu Kesehatan Anak FK USU, 2014.

6. Wu JR, Chen IC, Dai ZK, Hung JF, Hsu JH. Early elevated Btype natriuretic peptide levels are associated with cardiac dysfunction and poor clinical outcome in pediatric septic patients Acta Cardiol Sin. 2015; 31:485-93.

7. Maeder M, Fehr T, Rickli H, Ammann P. Sepsis-associated myocardial dysfunction diagnostic and prognostic impact of cardiac troponins and natriuretic peptides. Chest. 2006; 129:1349-66. https://doi.org/10.1378/chest.129.5.1349 PMid:16685029

8. Samsu N, Sargowo D. Sensitivitas dan spesifisitas troponin T dan I pada diagnosis infark miokard akut. Maj Kedokt Indon. 2007; 57:363-72.

9. Letreutre S, Duhamel A, Grandbastien B, Proulx F, Cotting J, Gottesman R, et al. Daily estimation of the severity of multiple organ dysfunction syndrome in critically ill children. CMAJ. 2010; 182(11):1181-7. https://doi.org/10.1503/cmaj.081715 PMid:20547715 PMCid:PMC2917930

10. Leteurtre S, Duhamel A, Deken V, Lacroix J, Leclerc F. Daily estimation of the severity organ dysfunctions in critically ill children by using the PELOD-2 score. Crit Care. 2015; 19(324):1-5. https://doi.org/10.1186/s13054-015-1054-y PMid:26369662 PMCid:PMC4570178

11. Singer M, Deutchman, Seymour CW, Shankar-Hari M, Annane $D$, Baurer $M$, et al. The third international consensus definitions for sepsis and septic shock (Sepsis-3). JAMA. 2016; 315(8):801-10. https://doi.org/10.1001/jama.2016.0287 PMid:26903338 PMCid:PMC4968574

12. Wang Y, Sun B, Yue H, Li B, Yang X, Shan C, et al. An epidemiologic survey of pediatric sepsis in regional hospitals in China. Pediatr Crit Care Med. 2014; 15(9):814-20. https://doi.org/10.1097/PCC.0000000000000247 PMid:25226498

13. Jaramillo-Bustamante JC, Marin-Agudelo A, FernandezLaverde M, Bareno-silva J. Epidemiology of sepsis in pediatric intensive care units: first Columbian multicentre study. Pediatr Crit Care Med. 2012; 13(5):501-8.

https://doi.org/10.1097/PCC.0b013e31823c980f PMid:22460772

14. Weiss L, Fitzgerald JC, Pappachan J, Wheeler D, JaramilloBustamante JC, Salloo A, et al. Global epidemiology of pediatric severe sepsis: the sepsis prevalence, outcomes, and therapies 
study. Am J Respir Crit Care Med. 2015; 190(10):1147-57. https://doi.org/10.1164/rccm.201412-23230C PMid:25734408 PMCid:PMC4451622

15. Karam O, Demaret $P$, Duhamel A, Shefler A, Spinella PC,dkk. Performance of the Pediatric Logistic Organ Dysfunction-2 score in critically ill children requiring plasma transfusions. Ann intensive care. 2016; 6:98. https://doi.org/10.1186/s13613-016-0197-6 PMid:27714707 PMCid:PMC5053948

16. Klag T, Cantara G, Sechtem U, athanasiadis A. Interleukin-6 kinetics can be useful for early treatment monitoring of severe bacterial sepsis and septic shock. Infectious disease reports. 2016; 8:6213. https://doi.org/10.4081/idr.2016.6213 PMid:27103972 PMCid:PMC4815941

17. Bessiere F, Khenifer S, Duvourg J, Durieu I, Lega JC. Prognostic value of troponin in sepsis: a meta-analysis. Intensive care med. 2013; 39:1181-89. https://doi.org/10.1007/s00134-0132902-3 PMid:23595497

18. Marlies O, Salma A, Emma T, Jessica L, Katie L, John S. Cardiac troponin release is associated with biomarkers of inflammation and ventricular dilatation during critical illness. SHOCK. 2017; 47:702-8.

https://doi.org/10.1097/SHK.0000000000000811 PMid:27902530 PMCid:PMC5419814

19. Kakihana $Y$, Ito T, Nakahara M, Yamaguchi K, Yasuda T. Sepsis induced myocardial dysfunction: pathophysiology and management. J Intensive Care. 2016; 4:22-9. https://doi.org/10.1186/s40560-016-0148-1 PMid:27011791 PMCid:PMC4804632

20. Rudiger A, Singer M. Mechanism of sepsis induced cardiac dysfunction. Crit Care Med. 2007; 35(6):1599-608. https://doi.org/10.1097/01.CCM.0000266683.64081.02 PMid:17452940

21. Hassan B, Morsy S, Siam A, Ali AS, Ando M, Shafie MA, et al. Myocardial injury in critically ill children: a case control study. ISRN Cardiol. 2014; 2014:1-4. https://doi.org/10.1155/2014/919150 PMid:24660069 PMCid:PMC3934765
22. Lodha R, Arun S, Vivekanandhan S, Kohli U, Kabra SK. Myocardial cell injury is common in children with septic shock. Acta Paediatr. 2009; 98:478-81. https://doi.org/10.1111/j.1651. 2227.2008.01095.x PMid:18976355

23. Khilnani $P$, Singhi S, Lodha R, Santhanam I, Sachdev A, Chugh K. Pediatric sepsis guidelines: summary for resource-limited countries. Indian J Crit Care Med. 2010; 14(1):41-52. https://doi.org/10.4103/0972-5229.63029 PMid:20606908 PMCid:PMC2888329

24. Wheeler DS, Wong HR. Sepsis in pediatric cardiac intensive care. Pediatr crit care med. 2016; 17(8):5266-71. https://doi.org/10.1097/PCC.0000000000000796 PMid:27490609 PMCid:PMC4975434

25. Eldeen SS, Khalaf MM, Hadidy KE. Cardiac troponin I as marker of sepsis severity and mortality prediction. Med K Cairo Univ. 2012; 80:167-72.

26. Sheyin O, Davies O, Duan W, Perez X: The prognostic significance of troponin elevation in patients with sepsis: a metaanalysis. Heart Lung. 2015; 44(1):75-81. https://doi.org/10.1016/j.hrtlng.2014.10.002 PMid:25453390

27. Bessiere F, Khenifer S, Duvourg J, Durieu I, Lega JC. Prognostic value of troponin in sepsis: a meta-analysis. Intensive care med. 2013; 39:1181-89. https://doi.org/10.1007/s00134-0132902-3 PMid:23595497

28. Gurkan F, Alkaya A, Ece A, Haspolat K, Bosnak M, Bilici M, et al. Cardiac troponin-I as a marker of myocardial dysfunction in children with septic shock. Swiss med wkly. 2004; 134:593-96.

29. John J, Woodward DB, Wang Y, et al. Troponin-I as a prognostic factor of mortality in severe sepsis patients. J Crit Care 2010; 25:270-75. https://doi.org/10.1016/j.jcrc.2009.12.001 PMid:20149590 